\title{
Kinetic Studies of Charge Transfer Formation of Erythromycin and 2, 3 Dichloro-5, 6-Dicyano -1,4- Benzoquinone
}

\author{
Nwanisobi Gloria ${ }^{1 *}$ and Ukoha Pius ${ }^{2}$ \\ 1Department of Chemical Engineering, Madonna University Nigeria, Nigeria \\ 2Department of Pure and Industrial Chemistry, University of Nigeria, Nigeria
}

Submission: March 20, 2018; Published: April 04, 2018

"Corresponding author: Nwanisobi Gloria, Department of Chemical Engineering, Madonna University Nigeria, Akpugo campus, Nigeria;

Tel: +2348052240626; Email: glochinwa4real@yahoo.com

\begin{abstract}
The kinetics of erythromycin with 2, 3 dichloro-5,6-dicyano -1,4- benzoquinone [DDQ] is described for the determination of erythromycin. It was carried in aqueous $\mathrm{HClO}_{4}(2 \mathrm{M})$ medium at ionic strength of $0.01 \mathrm{moldm}^{-3}$, Kinetics of the reactions infer that the rate of formation of the charge transfer complex did not vary significantly with increase in concentration of erythromycin indicating likely zeroth order dependence of the rate with respect to concentration of the drug. However, the linearity of the pseudo-first order plot points to first order dependence of rate on [DDQ].The overall rate equation for the reactions can be given as
\end{abstract}

$$
-\frac{d[D D Q]}{d t}=k_{o b s}[D D Q]
$$

Keywords: Kinetic studies; Erythromycin; Charge transfer; DDQ

\section{Introduction}

The kinetic methods of analysis are highly sensitive, selective, simple, accurate and less expensive [1]. Erythromycin, 3R, 45 55, 6R, 7R, 9R, 11R, 12R, 13R, 14R - 4-[(2,6-didiocy -3-c-methy 1-3-0-methy 1 -a-l-ribo -hexopy- ransyi) oxy]- 14 ethy 1-7, 12,13-trihydroxy- 3, 5,7,9,11,13-hexamethy 1-6-[(3,4,6-trideoxy -3-dimethy kmiro - P-D-xylo-hexopy ransoyl) -oxy] oxa cydofetradecare -2, 10-dione is a macrolide antibiotic used for the treatment of urinary tract infection. It targets at the ribosome and inhibits the protein synthesis of gram positive bacteria such as mycoplasma and Chlamydia [2]. In recent years, several kinetic catalytic techniques have been reported for the detection of biomolecules $[3,4]$. Literature revealed different techniques for the analysis of erythromycin as follows: spectrofluorimetry [5]. Capillary electrophoresis [6], HPLC [7], microbiological method [8] spectrophotometry $[9,10]$. Therefore, the aim of this research is to determine a kinetic method based on formation of charge transfer complex between erythromycin and DDQ that is simple, fast, economical and less laborious.

\section{Materials and Methods}

\section{Equipment}

All kinetic measurements were carried out using a UV1800 Shidmazu and 752 w UV - Vis grating with a silica glass cell of $1 \mathrm{~cm}$ thickness. All chemicals were of analytical grade and were used as such. Erythromycin powder was supplied by AC pharmaceutical limited, Enugu, Nigeria. The commercial erythromycin tablet (500mg per tablet) was purchased from the local market (Syncom formulations limited, India) 2,3 dichloro - 5, 6- dicyano-1,4-benzoquinone (98\% purity) was supplied by sigma Aldrich, Germany.

\section{Kinetic Measurements}

Kinetics of the reactions of DDQ with erythromycin was followed spectrophotometrically under pseudo-first order condition with one of the reactants (donor) in at least 10 fold in excess over the reactant (acceptor) at $29^{\circ} \mathrm{C}$. The pseudofirst order rate constants were determined by using various concentrations of erythromycin $(0.001 \mathrm{M}$ to $0.0035 \mathrm{M})$ with fixed concentration of acceptor (2.5 x10-4 M). Effects of ionic strength, $\mathrm{pH}$ and hydrogen ion on the rates of reaction were also determined.

The pseudo-first order rates constant were obtained from a plot of log versus time following equation 1.

$$
\left(A_{\alpha}-A_{t}\right)=\left(A_{\alpha}-A_{0}\right) e^{o b s^{-k t}}
$$




\section{Organic \& Medicinal Chemistry International Journal}

where $A_{\alpha}$ and $A_{0}$ are the final and initial absorbencies respectively, At is absorbance at time $t$ and $\mathrm{K}_{\mathrm{obs}}$ is pseudo-first order rate constant.

\section{Effect of Hydrogen Ion Concentration on the Rate of Erythromycin and DDQ Reaction}

Within the hydrogen ion concentration range $1.0 \times 10$ 2 to $1.0 \mathrm{~mol} \mathrm{dm}^{-3}$, kinetic runs were carried out keeping the concentrations of the drug and reagent constant at $\mathrm{I}=1.02 \mathrm{~mol}$ $\mathrm{dm}^{-3}$ and $\mathrm{T}=30.0 \pm 0.2^{\circ} \mathrm{C}$.

\section{Effect of Ionic Strength on the Rate of Erythromycin- DDQ Reaction}

Within the range of ionic strength of the media 0.001$0.03 \mathrm{~mol} \mathrm{dm}-3$, the variation of rate of reaction with ionic strength was investigated for the reaction of erythromycin and $\mathrm{DDQ}$, At $\mathrm{T}=28^{\circ} \mathrm{C}$ and keeping the concentrations of drug and reagent constant, the ionic strength was varied and the rate of plot is represented in Figure 1. reaction monitored.

\section{Results and Discussion}

\section{Reaction of Erythromycin with DDQ}

The wavelength of maximum absorption spectrum was found to be $464 \mathrm{~nm}$ with a stoiochiometric ratio of 1:1 of erythromycin - DDQ complex [11].

\section{Kinetic Studies}

The rate of the charge transfer reaction of erythromycin and DDQ was followed spectrophotometrically under pseudo - first order conditions by monitoring the rate of consumption of DDQ at $464 \mathrm{~nm}$. Erythromycin was at least 10 fold in excess of DDQ and the reaction was carried out at $\mathrm{pH}$ 8.Kinetic decays were exponential and pseudo first rate constants were determined from the plots of log versus time according to equation 1 . The plots were linear for more than $90 \%$ extent of reaction. Typical

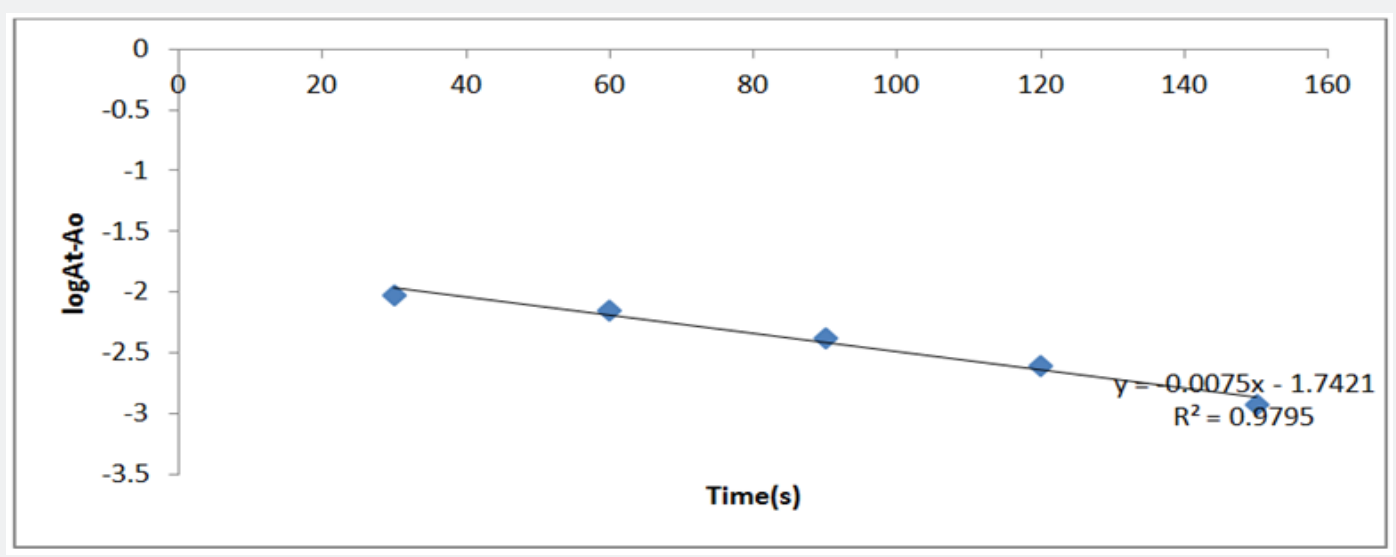

Figure 1

Table 1: Values of pseudo-first order and second order rate constants for the formation of erythromycin-DDQ reaction, $[D D Q]=10^{-3} \mathrm{M}$ at $30^{\circ} \mathrm{C}$.

\begin{tabular}{|c|c|c|c|}
\hline Vol of Erythromycin (10-2 $\mathbf{M})$ & Vol of Methanol $\left(\mathbf{c m}^{\mathbf{3}}\right)$ & $\mathbf{k}_{\text {obs }}\left(\mathbf{s}^{-1)}\right.$ & 0.016 \\
\hline 0.4 & 1.2 & 0.016 & 0.2 \\
\hline 0.6 & 1.0 & 0.0138 & 3.33 \\
\hline 0.8 & 0.8 & 0.0138 & 2.0 \\
\hline 1.0 & 0.6 & 0.0115 & 0.67 \\
\hline 1.2 & 0.4 & 0.0115 & 0.57 \\
\hline
\end{tabular}

$\mathrm{NaClO}_{4}=1.02 \mathrm{M},[$ Erythromycin $]=2.0 \times 10^{-5} \mathrm{M},[D D Q]=1 \times 10^{-6} \mathrm{M}$

The second order rate constants were determined by dividing $\mathrm{K}_{\mathrm{obs}}$ with [erythromycin]. The values of $\mathrm{K}_{\mathrm{obs}}$ and $\mathrm{k}_{2}$ are represented in Table 1 . The result from table 1 shows that as concentration of erythromycin increased from $0.001 \mathrm{M}$ to $0.0035 \mathrm{M}$, the Kobs values did not vary significantly indicating a zero order dependence on reaction rate with respect to the concentration of erythromycin. However, the linearity of the pseudo - first order plot points to first - order dependence of rate with respect to [DDQ].

\section{Effect of Hydrogen Ion Concentration on Erythromycin - DDQ Complex}

The $\mathrm{H}+$ concentration was varied from $0.08 \mathrm{M}$ to $1 \mathrm{M}$ while keeping other variables constant. Table 2 shows that Kobs increase from $0.08 \mathrm{M}$ to $1 \mathrm{M}$. This infers that within this acid concentration range, protonation of the reactants played significant role in the charge transfer reaction. The Second order rate constants were determined by dividing Kobs with[erythromycin]. Table 2 is a display of pseudo-first order and second order rate constants. 
Table 2: Acid values for the pseudo-first order and second order rate constant of erythromycin-DDQ complex at $\Lambda_{\max }=464 \mathrm{~nm}, \mathrm{~T}=30^{\circ} \mathrm{C}$ $\mathrm{NaClO}_{4}=1.02 \mathrm{M}$, [Erythromycin] $=2.0 \times 10-5 \mathrm{M},[\mathrm{DDQ}]=1 \times 10^{-6} \mathrm{M}$

\begin{tabular}{|c|c|c|}
\hline I (mold m $\left.{ }^{-3}\right)$ & $k_{\text {obs }}\left(s^{-1}\right)$ & $\mathrm{k}_{2} \times 10^{2}\left(\mathrm{dm}^{3} \mathrm{~mol}^{-1} \mathrm{~s}^{-1}\right)$ \\
\hline 0.001 & 0.005 & 2.5 \\
\hline 0.005 & 0.005 & 2.5 \\
\hline 0.01 & 0.005 & 2.5 \\
\hline 0.015 & 0.002 & 1.0 \\
\hline 0.02 & 0.009 & 4.5 \\
\hline 0.025 & 0.009 & 4.5 \\
\hline 0.03 & 0.002 & 1.0 \\
\hline
\end{tabular}

Effect of Ionic Strength on Erythromycin - DDQ Complex

In addition, ionic strength medium was varied from $0.001 \mathrm{M}$ to $0.03 \mathrm{M}$. Table 3 shows that $\mathrm{K}_{\mathrm{obs}}$ did not vary significantly at $0.001 \mathrm{M}-0.01 \mathrm{M}$ but increased from $0.015 \mathrm{M}$ to $0.025 \mathrm{M}$ of the varied ionic strength which indicates primary salt effect and likely involvement of charged partners at the rate determining step.

Table 3: Effect of ionic strength on the rate of erythromycin-DDQ reaction at $\Lambda \max =464 \mathrm{~nm}, \mathrm{~T}=30^{\circ} \mathrm{C}, \mathrm{NaClO}_{4}=0.1 \mathrm{M}$, [Erythromycin] $=2.0 \times 10^{-5} \mathrm{M},[\mathrm{DDQ}]=1 \times 10^{-6} \mathrm{M}$.

\begin{tabular}{|c|c|c|}
\hline I $\left(\right.$ mold m $\left.{ }^{-3}\right)$ & $k_{\text {obs }}\left(s^{-1}\right)$ & $\begin{array}{c}\mathrm{k}_{2} \times 10^{2}\left(\mathrm{dm}^{3} \mathrm{~mol}\right. \\
\left.{ }^{1} \mathbf{s}^{-1}\right)\end{array}$ \\
\hline 0.001 & 0.005 & 2.5 \\
\hline 0.005 & 0.005 & 2.5 \\
\hline 0.01 & 0.005 & 2.5 \\
\hline 0.015 & 0.002 & 1.0 \\
\hline 0.02 & 0.009 & 4.5 \\
\hline 0.025 & 0.009 & 4.5 \\
\hline 0.03 & 0.002 & 1.0 \\
\hline
\end{tabular}

\section{Effect of Temperature on Erythromycin - DDQ Complex}

Effect of temperature was studied between $303 \mathrm{k}-333 \mathrm{k}$. Result in (Table 4) shows a drop in $\mathrm{K}_{\mathrm{obs}}$ from $313 \mathrm{k}$ to $333 \mathrm{k}$, this shows that as the temperature increases, the rate of reaction decreased. Also, Table 4 reveals a negative entropy, negative enthalpy change and positive Gibb's free energy change which means that the reaction does not occur spontaneously.

Least square fit of log $\mathrm{K}_{\mathrm{obs}} / \mathrm{T}$ vs $1 / \mathrm{T}$ based on the Eyring - Polanyi [12] (equation 2) is represented in Figure 2.

$$
k_{r}\left(\frac{K T}{h}\right) \exp \left(\frac{\Delta S^{\#}}{R}\right) \exp \left(\frac{-\Delta H^{\#}}{R T}\right)
$$

Where, $\mathrm{kr}=$ rate constant, $\mathrm{k}=$ Boltzmann's constant, $\mathrm{h}=$ Planck's constant, $\Delta \mathrm{S} \#=$ entropy of activation $\Delta \mathrm{H} \#=$ enthalpy of activation, $\mathrm{T}=$ absolute temperature $\mathrm{R}=$ gas constant.

The rate determining steps of erythromycin-DDQ complex are as follows:

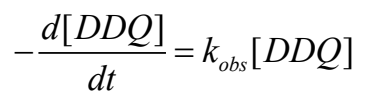<smiles>COC1C(Cl)=C(Cl)C(=O)C(C#N)=C1C#N</smiles>
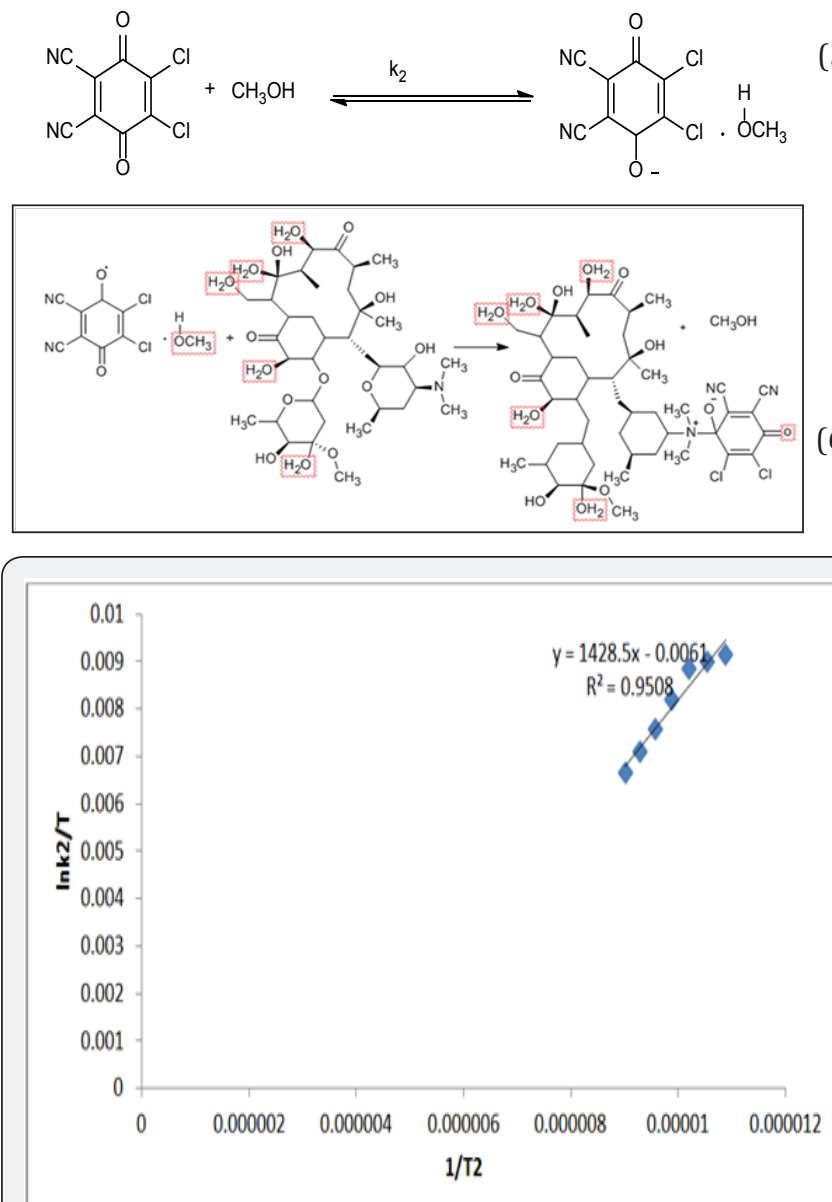

Figure 2

Table 4: Effect of temperature on the pseudo-first order rate constant and activation parameters for the formation of erythromycin-DDQ

complex at $\Lambda_{\max }=464 \mathrm{~nm},[$ Erythromycin $]=10^{-2} \mathrm{M},[D D Q]=10^{-3} \mathrm{M}$.

\begin{tabular}{|c|c|c|c|}
\hline $\begin{array}{c}\text { Temperature } \\
\left({ }^{\circ} \mathrm{C}\right)\end{array}$ & $\underset{\left.\mathrm{mol}^{-1}\right)}{\Delta \mathrm{G}^{0} \times \mathbf{1 0}^{5}(\mathrm{~kJ}}$ & $k_{o b s}\left(s^{-1}\right)$ & $\begin{array}{c}\mathrm{k}^{2}\left(\mathrm{dm}^{3} \mathrm{~mol}\right. \\
\left.{ }^{1} \mathrm{~s}^{-1}\right)\end{array}$ \\
\hline 30 & 7.25 & 0.016 & 16 \\
\hline 35 & 7.37 & 0.016 & 16 \\
\hline 40 & 7.49 & 0.016 & 16 \\
\hline 45 & 7.61 & 0.01375 & 13.75 \\
\hline 50 & 7.73 & 0.0115 & 11.5 \\
\hline 55 & 7.84 & 0.01035 & 10.35 \\
\hline 60 & 7.96 & 0.0092 & 9.2 \\
\hline
\end{tabular}

$\Delta \mathrm{S} \#\left(\mathrm{kJk}^{-1} / \mathrm{mol}\right)=-2391 ; \Delta \mathrm{H} \#\left(\mathrm{~kJ} \mathrm{~mol}^{-1}\right)=-11$ 


\section{Organic \& Medicinal Chemistry International Journal}

\section{Conclusion}

The proposed kinetic method infer that the rate of formation of charge transfer complexes did not vary significantly with increase in concentration of erythromycin indicating a likely zeroth order dependence of the rate with respect to the concentration of erythromycin. However, the linearity of the pseudo - first order plot points to first order dependence of rate on [DDQ].

\section{References}

1. Mohammed l, Maqsood A, Syed M, Zaheer K (2007) Kinetics and mechanism of paracetamol oxidation by chromium (VI) in absence and presence of manganese (II) and sodiumdodecyl sulphate Research letters in physical chemistry.

2. Onura S Macrolide Antibiotics Chemistry, Biology and Practice. Academic Press Orlando, USA, p. 26.

3. Nandibewoor ST, Morah VA (1995) Chromium (III) Catalysed Oxidation of Antimony (III) by Alkaline hexacyanoferrate (III) and Analysis of chromium (III) in microamounts by kinetic method. Journal of the chemical society, Dalton 3: 483-488.

4. Imdadullar TF, Karmamaru (1994) Catalytic Effect of Rhodium (III) on the Chemiluminescence of Luminal in Reverse Miscelles and its Analytical Application. Analytica Chimica Acta 292(1-2): 151-157.

5. Pakinaz YK (2002) Spectrophotometric Analysis of Certain Macrolide Antibiotics in bulk and Pharmaceutical Formulation. Journal of Pharmaceutical and Biomedical Analysis 27(6): 923-932.
6. Nawal R, Hassan F, Pakiraz K, Noha N, Attia A (2006) Validated Spectrophotometric Assay for the Determination of Certain Macrolide Antibiotics in Pharmaceutical Formations and Spiked Biological Fluidss, J AOAC Int 89(5): 1276-1287.

7. Maria H, Britt E (1995) Liquid Chromatographic Determination of the Macrolide Antibiotics Toxithromycin and Clarithromycin in Plasma by Automated Solid-Phase Extraction and Electrochemical Detection. J Chromatogr A 692 (1-2): 161-166.

8. Bernabeu JA, Camacho MA, Gilalegre ME, Ruz V, Towes S (1999] Microbiology Bioassay of Erythromycin Thiocyanate: Optimization and Validation. J Pharm biomed Anal 21(2): 347-353.

9. Carlos E, Paula R, Vanessa GK, Almeida R, Cassella J (2010) Novel Spectrophotometric Method for the Determination of Azithromycin in Pharmaceutical Formulations based on its Charge Transfer Reaction with Quinalization. Journal of Brazillian Chemical Society 21: 16641671.

10. Safwan A, Roula B (2012) Novel Spectrophotometric Method for Determination of some Macrolide Antibiotics in Pharmaceutical Formulations using 1,2-naphthoquinone-4- sulphonatae. Spectrochim Acta Part A 99: 74-80.

11. Ukoha O Pius, Nwanisobi C Gloria (2016) Spectrophotometric Determination of Erythromycin using Charge Transfer Complexation. Der Pharma Chemica 8(2): 59-66.

12. Petr P, Tomas O, Frantisek S (2016) Introduction of Novel Kinetic approach to Calculation of Activation Energy and its Application to the Sinter-Crystallization of Strontian Feldspar. Ceramics International 42(15): 16969-16980.

Your next submission with Juniper Publishers
will reach you the below assets
- Quality Editorial service
- Swift Peer Review
- Reprints availability
- E-prints Service
- Manuscript Podcast for convenient understanding
- Global attainment for your research
- Manuscript accessibility in different formats
( Pdf, E-pub, Full Text, Audio)
- Unceasing customer service
Track the below URL for one-step submission
https://juniperpublishers.com/online-submission.php

